\title{
Percepción de riesgo, automedicación, mitos y creencias relacionados con COVID-19 entre jefes de hogar peruanos
}

\author{
Risk perception, self-medication, myths, and beliefs related \\ with COVID-19 among Peruvian head of households \\ Luis C. Cano-Gómez ${ }^{\circledR}$; René D. Castillo-Tejada ${ }^{2}$; Sissy S. Mena-Ordoñez ${ }^{{ }^{*}(\mathbb{1}}$ \\ *sissymena@hotmail.com
}

Forma de citar: Cano Gómez LC, Castillo Tejada RD, Mena Ordoñez SS. Percepción de riesgo, automedicación, mitos y creencias relacionados con COVID-19 entre jefes de hogar peruanos. Salud UIS. 2022; 54: Salud UIS. 2022; 54: e22003. doi: https://doi.org/10.18273/saluduis.54.e:22003 @) (1)

Resumen

Introducción: a más de un año del inicio de la pandemia COVID-19, el número de contagiados y muertes aún presenta frecuencias que escapan al control de manejo hospitalario. Aunado al temor, se acrecentó la aparición de mitos, creencias, automedicación e inadecuada percepción de riesgo en la población. Objetivo: identificar la percepción de riesgo, automedicación, mitos y creencias de prevención respecto al COVID-19 en adultos jefes de hogar del distrito Gregorio Albarracín de Tacna en el 2020. Material y métodos: se aplicó una encuesta a una muestra representativa de 250 jefes de hogar, residentes en el distrito Gregorio Albarracín. Resultados: el promedio total del grupo en percepción del riesgo expresado en porcentaje fue de $60,96 \%(59,81-62,11)$ de un total de probable esperado ideal de $100 \%$. La percepción de "estar en riesgo en la pandemia" es baja. Solo el 15,20 \% acató el aislamiento domiciliario estricto cuando fue indicado. El 14,8 \% se automedicaba y en este grupo, los productos usados fueron Ivermectina $(48,6 \%)$ y dióxido de cloro $(45,9 \%)$. Los mitos y creencias más frecuentes fueron "rociarse con alcohol o cloro mata el virus" y "los remedios caseros pueden curar o prevenir el coronavirus". Hubo diferencia según edad $(\mathrm{p}<0,05)$, nivel de instrucción $(\mathrm{p}<0,001)$. Conclusiones: la automedicación estuvo fuertemente asociada con elevada percepción de riesgo $(\mathrm{p}<0,001)$ y presencia de mitos y creencias $(\mathrm{p}<0,001)$. El nivel de instrucción estuvo altamente asociado con la presencia de mitos y creencias $(\mathrm{p}<0,001)$

Palabras clave: Coronavirus; COVID-19; Automedicación; Percepción; Mitos y creencias

1. Universidad Privada de Tacna. Perú.

2. Hospital Daniel Alcides Carrión, Essalud, Tacna, Perú. 


\section{Abstract}

Introduction: More than a year after the beginning of the COVID-19 pandemic, the number of infections and deaths is still beyond the control of hospital management. In addition to fear, myths, beliefs, self-medication and inadequate risk perception in the population have increased. Objective: To identify the perception of risk, self-medication, myths and prevention beliefs regarding COVID-19 in adult heads of household in the Gregorio Albarracín district of Tacna in 2020. Method: A survey was administered to a representative sample of 250 heads of household residing in the Gregorio Albarracín district. Results: The total average of the group in risk perception expressed as a percentage was $60.96 \%$ (59.81-62.11) out of a total expected ideal of $100 \%$. The perception of "being at risk in the pandemic" is low. Only $15.20 \%$ adhered to strict home isolation when instructed to do so. The $14.8 \%$ self-medicated and in this group, the products used were ivermectin $(48.6 \%)$ and chlorine dioxide $(45.9 \%)$. The most frequent myths and beliefs were "spraying with alcohol or chlorine kills the virus" "home remedies can cure or prevent coronavirus"; there were differences according to age $(p<0.05)$ and educational level $(p<0.001)$. Conclusions: self-medication was strongly associated with high-risk perception $(p<0.001)$ and presence of myths and beliefs $(\mathrm{p}<0.001)$. Educational level was highly associated with the presence of myths and beliefs $(\mathrm{p}<0.001)$.

Keywords: Coronavirus; COVID-19; Self-Medication; Perception; Myths and beliefs

\section{Introducción}

La enfermedad del COVID-19, causada por el virus SARS-CoV-2, afecta principalmente al sistema respiratorio y desde marzo del 2020 se catalogó como una nueva pandemia. La difusión por diversos medios de contagio, mortalidad, aunado a una producción enorme de información de diversa procedencia, acrecentaron la aparición de mitos y creencias (género popular compuesto de narraciones/historias que juegan un papel vital en la vida diaria humana) $)^{11}$, automedicación y percepciones de riesgo frente a la enfermedad en forma exagerada o en muchos casos con conductas de alta irresponsabilidad en la población. El objetivo de la presente investigación fue identificar el nivel de riesgo que percibe el poblador respecto al contagio, características de automedicación, mitos y creencias en el contexto de la pandemia por COVID-19, en adultos jefes de hogar de un distrito en el Perú, el cual fue catalogado como de nivel de riesgo "muy alto" al 11 de abril del 2021.

El virus (SARS-CoV-2) tiene una alta tasa de mortalidad (especialmente en ancianos o personas con comorbilidades de riesgo) y carece de tratamiento farmacológico efectivo ${ }^{2}$, aunque la vacuna es el tratamiento de prevención primaria actualmente más eficaz. Como estrategia de salud pública se cerraron escuelas y negocios para frenar la propagación de la infección. La comunicación por medios oficiales y la generada en redes sociales fue regularmente confusa para la población general ${ }^{3}$. Es claro que existe información limitada sobre mitos y creencias de la población sobre COVID-19 y la publicación médica confiable es sobrepasada por la de las redes sociales más asequibles, las cuales, algunas veces han difundido información positiva, y en otras negativa o muy confusa ${ }^{4,5}$. En un contexto donde la Organización Mundial de la Salud (OMS) ha elevado su evaluación de riesgo global de la enfermedad por coronavirus al nivel más alto ${ }^{6}$, los aislamientos extensos, indirectamente también alientan a las personas a pasar más tiempo en las redes sociales ${ }^{7}$, donde se hace difícil encontrar orientación confiable.

En América del Sur, Perú ocupa el tercer lugar en contagio $^{8}$. En este panorama, se necesita comprender mejor cómo perciben el riesgo las personas, y cómo las creencias y mitos generan conductas inadecuadas o de riesgo en el poblador, además que explicarían cómo, a pesar de los esfuerzos de prevención difundidos por medios oficiales, las tasas de infección aumentan y escapan al control. Esta es una enfermedad que ha provocado emergencias sociales y requiere esfuerzos conjuntos efectivos para reducir la transmisión ${ }^{9}$. Una de las primeras creencias que se vio a nivel mundial fue la posibilidad de escasez de productos básicos ${ }^{10}$, donde comunidades enteras comenzaron a almacenar artículos como papel higiénico ${ }^{11}$. Asimismo, la automedicación se hizo presente en forma vertiginosa; esta se define como el uso de medicamentos para tratar una enfermedad o síntoma mediante un autodiagnóstico, y se considera una práctica muy insegura e irresponsable ${ }^{12}$. De un subgrupo de 60 compañías farmacéuticas de la ciudad de Lima, 58 (96,7 \%) no requirieron recetas para distribuir antibióticos ${ }^{13}$. La evidencia anterior demuestra la importancia de los valores humanos y los valores compartidos de las personas para resolver la crisis COVID-19 14 , tanto de las personas que subestiman la posibilidad de infecciones personales, así como el asumir conductas de riesgo como la automedicación ${ }^{15}$. La percepción del riesgo es un determinante importante 
en las decisiones relacionadas con la salud, así como el comportamiento saludable, la reducción de hàbitos poco saludables y la aceptación o rechazo de determinantes sociales de riesgo ${ }^{16}$. Los mitos y creencias serán siempre un riesgo para la salud ${ }^{17} \mathrm{y}$, como tienen influencia cultural, pueden tener diversos grados de impacto en la sociedad $^{1}$.

\section{Metodología}

Se realizó una encuesta en el distrito Gregorio Albarracín Lanchipa de la región de Tacna-Perú, ciudad fronteriza con Chile y Bolivia, de alto tránsito entre estos tres países y declarada de "alto riesgo" ante la pandemia COVID-19. El tipo de muestreo fue bietápico y probabilístico e independiente. La localidad se dividió en 30 zonas por criterios de identificación geográfica catastral, cada una divida en asociaciones y manzanas. Se seleccionaron aleatoriamente 6 zonas. Para identificar las unidades primarias de muestreo se usó el Registro Municipal de Hogares (Área de Tributación). Para la segunda etapa se identificó la unidad secundaria de muestreo (hogares) utilizando un mapa cartográfico municipal actualizado para edificios y viviendas. Se identificaron aproximadamente 715 hogares habitados. Se calculó una muestra probabilística de 250 hogares, con un $95 \%$ de confianza, 0,5 de probabilidad de éxito y un 0,05 margen de error. En cada hogar identificado, la unidad de análisis fue: jefe de hogar con mayor ingreso económico aportante, con más de 6 meses de residencia, de ambos sexos, mayor de 18 años, responsable de manutención de los integrantes del hogar, nacionalidad peruana y presente al momento de la visita domiciliaria. Se excluyeron a familias en tránsito, a aquellos que no desearon participar y las viviendas cerradas o vacías. El instrumento de percepción del riesgo fue, en su versión corta, el BIP-Q5 ${ }^{18}$, traducidos al español y validado por
Pacheco-Huergo et al. ${ }^{19}$ Para el cuestionario de mitos y creencias se utilizó la selección validada propuesta por la Organización Mundial de la Salud, actualizada a junio de $2020^{1,20}$. Asimismo, se usó un cuestionario de variables sociodemográficas con indagación de las características de aislamiento social. La aplicación del instrumento de recolección de datos fue de tipo cuantitativo adaptado y validado para el servicio respaldado por publicaciones existentes y juicio de expertos. Se hizo una validación estadística mediante el uso de Alfa de Cronbach con un valor mínimo aceptable de 0,8 para cada reactivo de los instrumentos de recolección de datos de riesgo (BIP-Q5), mitos y creencias. Se usaron pruebas bivariadas para determinar las principales variables relacionadas. Se utilizaron medidas de tendencia central y dispersión, chi cuadrado y barras de error (análisis de varianza) para relación de variables de automedicación, percepción del riesgo, mitos y creencias. Se consideró un valor $p$ significativo menor a 0,05 .

\section{Resultados}

Del grupo que reconoce haberse automedicado (Figura 1) con medicamentos o productos no farmacéuticos $(n=37 / 250,14,8 \%)$, el 48,6 \% había ya consumido Ivermectina, seguido de un $45,9 \%$ de dióxido de cloro. El 27 \% refiere haber consumido Azitromicina independientemente de si estuvo acompañado de Ivermectina o no. Los productos más automedicados (Tabla 1) fueron adquiridos principalmente por el jefe de hogar, en farmacias, boticas o vendedores informales. Además, se observó que del grupo que almacenaba productos $(\mathrm{n}=47 / 250,18,8 \%)$, el $18,4 \%$ tenía ya almacenado Ivermectina, seguido de un 17,2\% de Azitromicina, principalmente. Solo un $8,4 \%$ tenía en reserva Paracetamol.

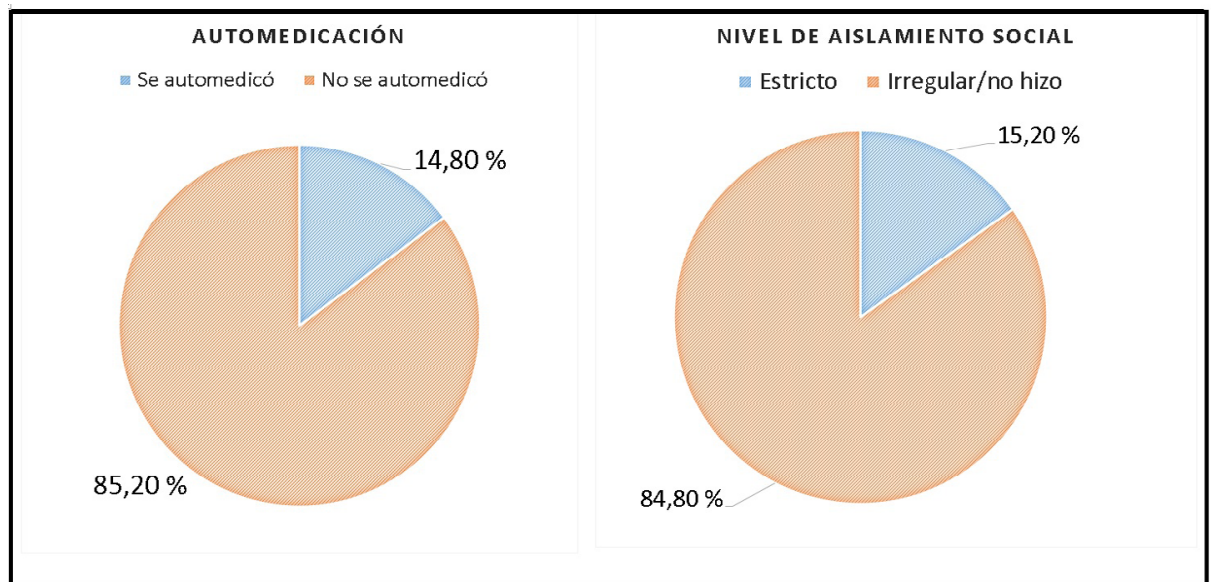

Figura 1. Automedicación y asilamiento social de los jefes de hogar 
La variable aislamiento, estrategia epidemiológica principal preventiva usada en la mayor frecuencia del brote (denominada “olas"), se dicotomizó para encontrar diferencia significativa según las variables propuestas (Figura 1).

Tabla 1. Distribución porcentual de medicamentos o productos automedicados en COVID-19 y con intención preventiva de los jefes de hogar.

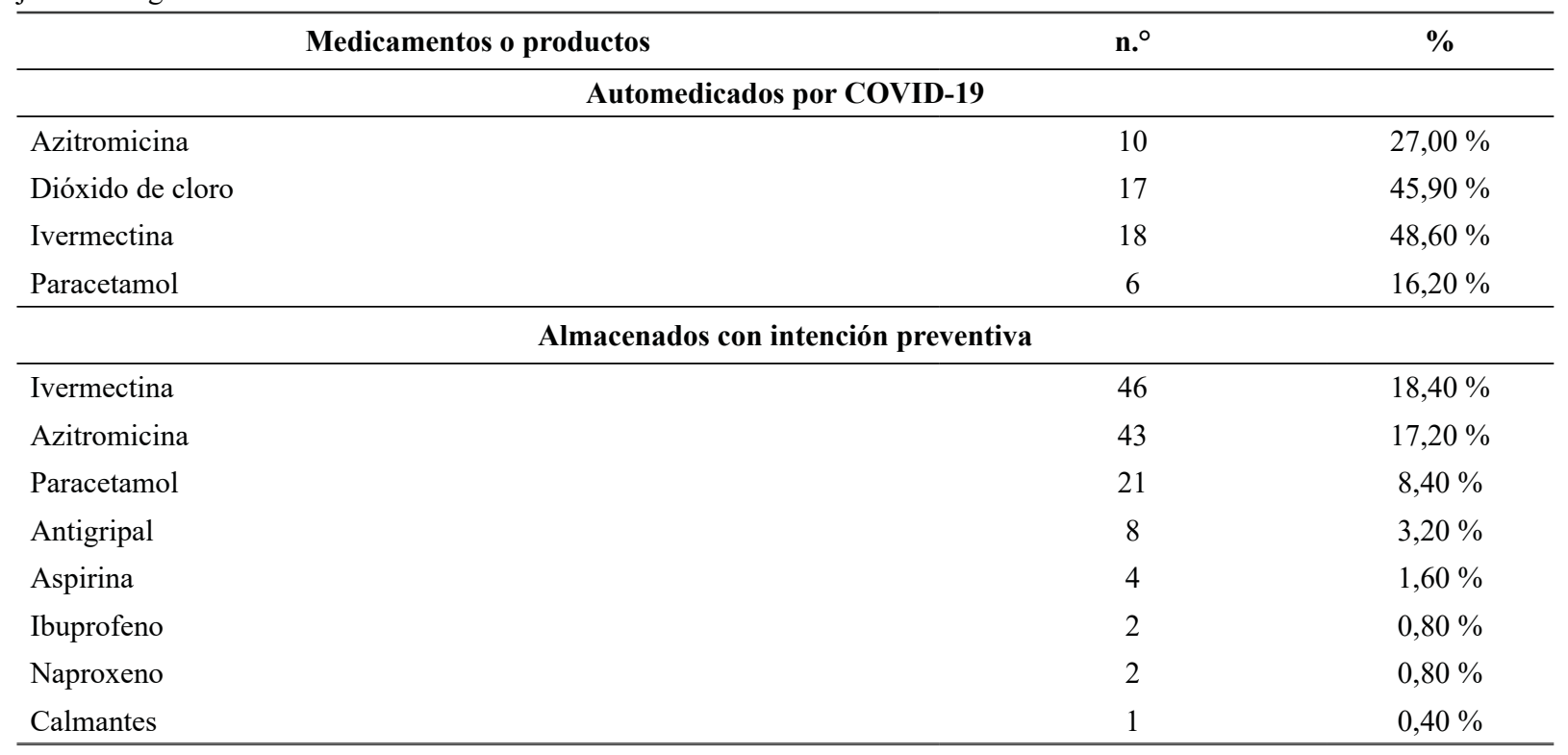

No se evidenció diferencia significativa según edad, sexo, estado civil y número de hijos y la probabilidad de automedicarse. Según edad, en el grupo de 19 a 29 años, el 18,8 \% se había automedicado, pero en aquellos de 70 años en adelante, el 20,4\% también lo había hecho. En las edades intermedias las diferencias no fueron estadísticamente significativas. Respecto al sexo, en el grupo de mujeres el 16,8\% se automedicaba, mientras que en el grupo de varones lo hizo el 12,4 \%; esta diferencia no fue significativa. En el grupo de solteros, viudos o divorciados no se marcó la diferencia proporcional, en el grupo de casados fue del $12,7 \%$ y en el grupo de convivientes el $14 \%$ que se automedicaron, por tanto, la diferencia no fue significativa $(\mathrm{p}>0,05)$. No existió mayor diferencia para acatar el aislamiento según edad, sexo, estado civil, número de hijos, nivel de instrucción u ocupación ( $>0,05$ ) (Tabla 2).

Respecto a la frecuencia de mitos y creencias (Tabla 3), el 93,2\% reconoce que el "lavado de manos mata el virus", pero se observan en alta frecuencia creencias negativas, donde el $67,6 \%$ cree que "rociarse con alcohol o cloro mata el virus", seguido de un 55,6 \% que asume que la "gárgara de agua con sal es eficiente para eliminar el virus".
Se valoró con un máximo de 100 puntos la acción correcta respecto a mitos y creencias y como 0 cuando estás eran aceptadas. El grupo en estudio solo alcanzó una media de 43,43 (D.E: 0,85). Dicha valoración cuantitativa continua sirvió para contrastarse según automedicación, percepción del riesgo y principales variables sociodemográficas.

La percepción del riesgo (Tabla 4) fue valorada en una escala de 0 a 10 para cada reactivo. El promedio más bajo fue para la "percepción de síntomas", y el mayor puntaje promedio (mejor percepción) fue respecto a la "duración de la pandemia". El valor de percepción de riesgo expresado en porcentaje alcanzó un promedio de $60,96 \%(59,81-62,11)$ de un total probable esperado ideal de $100 \%$, con una mediana de 50 . Se podría asumir que la percepción de "estar en riesgo en la pandemia" es baja.

Se observó que existe una marcada diferencia según la conducta de automedicación y percepción de riesgo. En el grupo que no se automedica, la percepción de riesgo es menor, estadísticamente diferente al grupo que sí se automedica $(\mathrm{p}<0,00)$ (Figura 2). 
Percepción de riesgo, automedicación, mitos y creencias relacionados con COVID-19 entre jefes de hogar peruanos

Tabla 2. Frecuencia de acatamiento de aislamiento según características sociodemográficas en jefes de hogar, 2020.

\begin{tabular}{|c|c|c|c|c|c|}
\hline & & \multicolumn{4}{|c|}{ Aislamiento $(p>0,05)$} \\
\hline & & \multicolumn{2}{|c|}{ Estricto } & \multicolumn{2}{|c|}{ Irregular/no hizo } \\
\hline & & $\mathrm{n}$ & $\%$ & $\mathrm{n}$ & $\%$ \\
\hline \multirow{5}{*}{ Edad } & 19 a 29 años & 0 & $0,00 \%$ & 16 & $100,00 \%$ \\
\hline & 30 a 39 años & 10 & $18,20 \%$ & 45 & $81,80 \%$ \\
\hline & 40 a 49 años & 10 & $13,70 \%$ & 63 & $86,30 \%$ \\
\hline & 50 a 59 años & 10 & $17,50 \%$ & 47 & $82,50 \%$ \\
\hline & 60 o más & 8 & $16,30 \%$ & 41 & $83,70 \%$ \\
\hline \multirow{3}{*}{ Sexo } & Femenino & 23 & $16,80 \%$ & 114 & $83,20 \%$ \\
\hline & Masculino & 15 & $13,30 \%$ & 98 & $86,70 \%$ \\
\hline & Total & 38 & $15,20 \%$ & 212 & $84,80 \%$ \\
\hline \multirow{4}{*}{ N. ${ }^{0}$ de hijos } & Ninguno & 4 & $16,00 \%$ & 21 & $84,00 \%$ \\
\hline & 1 a 2 & 25 & $13,70 \%$ & 157 & $86,30 \%$ \\
\hline & 3 a 5 & 9 & $22,00 \%$ & 32 & $78,00 \%$ \\
\hline & 6 o más & 0 & $0,00 \%$ & 2 & $100,00 \%$ \\
\hline \multirow{4}{*}{ Nivel de instrucción } & Sin instrucción & 0 & $0,00 \%$ & 5 & $100,00 \%$ \\
\hline & Primaria incompleta & 2 & $6,7 \%$ & 28 & $93,3 \%$ \\
\hline & Secundaria incompleta & 13 & $4,70 \%$ & 137 & $95,30 \%$ \\
\hline & Superior incompleta & 23 & $35,39 \%$ & 42 & $64,61 \%$ \\
\hline \multirow{4}{*}{ Ocupación } & Sin ocupación & 1 & $2,28 \%$ & 43 & $97,72 \%$ \\
\hline & Independiente formal & 16 & $10,26 \%$ & 140 & $89,74 \%$ \\
\hline & Dependiente contratado & 21 & $42,00 \%$ & 29 & $58,00 \%$ \\
\hline & Total & 38 & $15,20 \%$ & 212 & $84,80 \%$ \\
\hline
\end{tabular}

Tabla 3. Distribución de frecuencia de los mitos y creencias presentes en adultos jefes de hogar (n=250), 2020.

\begin{tabular}{|c|c|c|}
\hline Creencia y mitos & $n^{\cdot 0}$ & $\%$ \\
\hline El lavado de manos constante mata el virus & 233 & $93,2 \%$ \\
\hline Rociarse con alcohol o cloro mata al virus & 169 & $67,6 \%$ \\
\hline La gárgara de agua con sal mata al virus & 139 & $55,6 \%$ \\
\hline El uso y consumo de ajo mata al virus & 124 & $49,6 \%$ \\
\hline Los zapatos pueden propagar el virus & 117 & $46,8 \%$ \\
\hline Los síntomas más importantes son tos, fiebre y cansancio & 117 & $46,8 \%$ \\
\hline Los remedios caseros pueden curar el coronavirus & 111 & $44,4 \%$ \\
\hline El calor puede matar el virus & 89 & $35,6 \%$ \\
\hline La persona contagiada con el coronavirus morirá & 89 & $35,6 \%$ \\
\hline El uso prolongado de mascarilla provoca intoxicación por $\mathrm{CO}^{2}$ & 85 & $34,0 \%$ \\
\hline El coronavirus fue creado por el hombre & 83 & $33,2 \%$ \\
\hline Hay que usar mascarilla para hacer ejercicio físico & 82 & $32,8 \%$ \\
\hline La máscara quirúrgica previene la infección & 79 & $31,6 \%$ \\
\hline El uso de aspirina mezclado con limón mata el virus & 76 & $30,4 \%$ \\
\hline Los niños no se pueden contagiar por el coronavirus & 65 & $26,0 \%$ \\
\hline La infección por el virus tiene cura & 59 & $23,6 \%$ \\
\hline Solo el profesional de salud necesita máscaras & 58 & $23,2 \%$ \\
\hline Los antibióticos matan el virus & 51 & $20,4 \%$ \\
\hline Beber alcohol (vino, cerveza, wiski, etc.) mata al virus & 38 & $15,2 \%$ \\
\hline El virus puede transmitirse por correo electrónico & 3 & $1,2 \%$ \\
\hline
\end{tabular}

${ }^{\mathrm{a} C}$ reencias y mitos /OMS 
Tabla 4. Medición de la percepción del riesgo en adultos jefes de hogar, 2020.

\begin{tabular}{|c|c|c|c|c|c|}
\hline & & & Media & Máximo & Mínimo \\
\hline \multicolumn{3}{|c|}{ Cuánto afecta la infección por coronavirus a su vida } & 6 & 9 & 3 \\
\hline \multicolumn{3}{|c|}{ Cuánto cree durará la infección por coronavirus } & 7 & 10 & 3 \\
\hline \multicolumn{3}{|c|}{ En qué medida siente síntomas debido a la infección por coronavirus } & 4 & 8 & 1 \\
\hline \multicolumn{3}{|c|}{ En qué medida está preocupado por la infección por coronavirus } & 7 & 10 & 3 \\
\hline \multicolumn{3}{|c|}{ En qué medida le afecta emocionalmente la infección por coronavirus } & 7 & 10 & 3 \\
\hline \multirow{3}{*}{ Percepción de riesgo (\%) } & Media & \multicolumn{4}{|c|}{60,9680 IC $95 \%(59,81-62,11)$} \\
\hline & Mediana & \multicolumn{4}{|l|}{60} \\
\hline & Desviación estándar & \multicolumn{4}{|l|}{9,2} \\
\hline
\end{tabular}

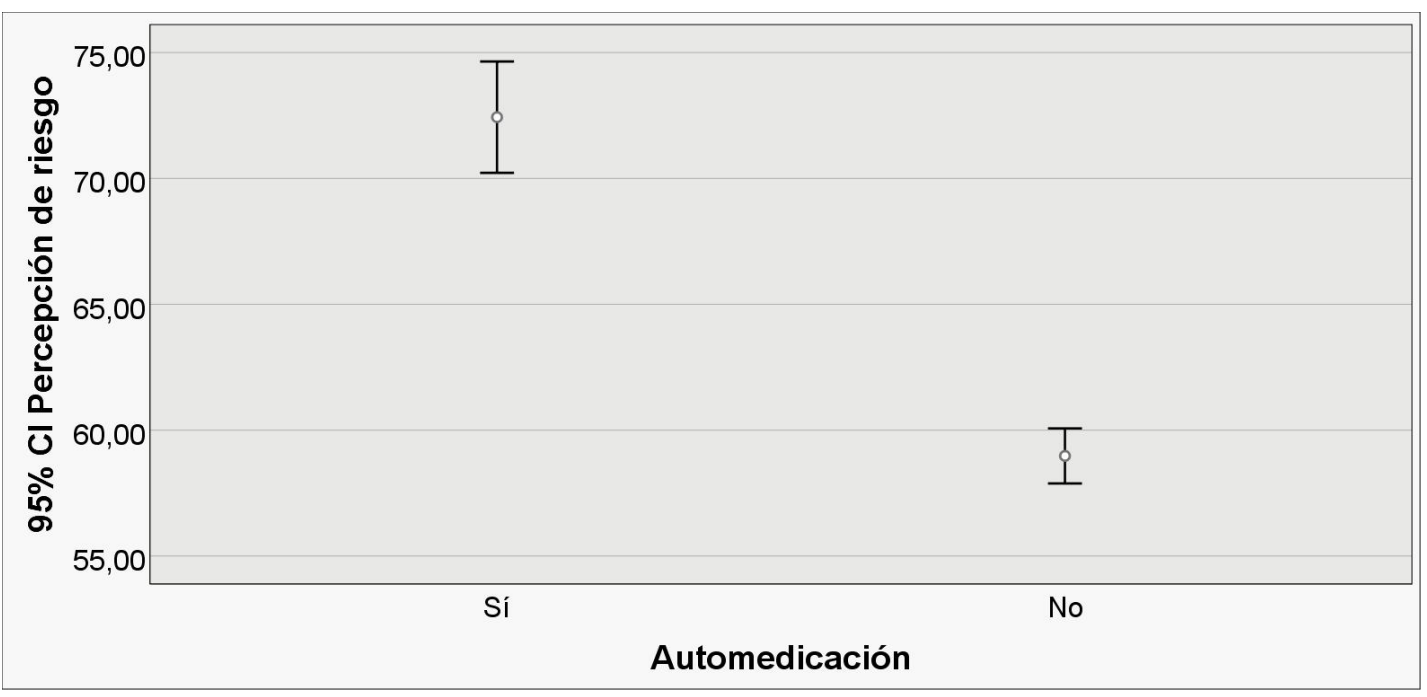

Figura 2. Puntaje de percepción del riesgo y automedicación en adultos jefes de hogar, 2020

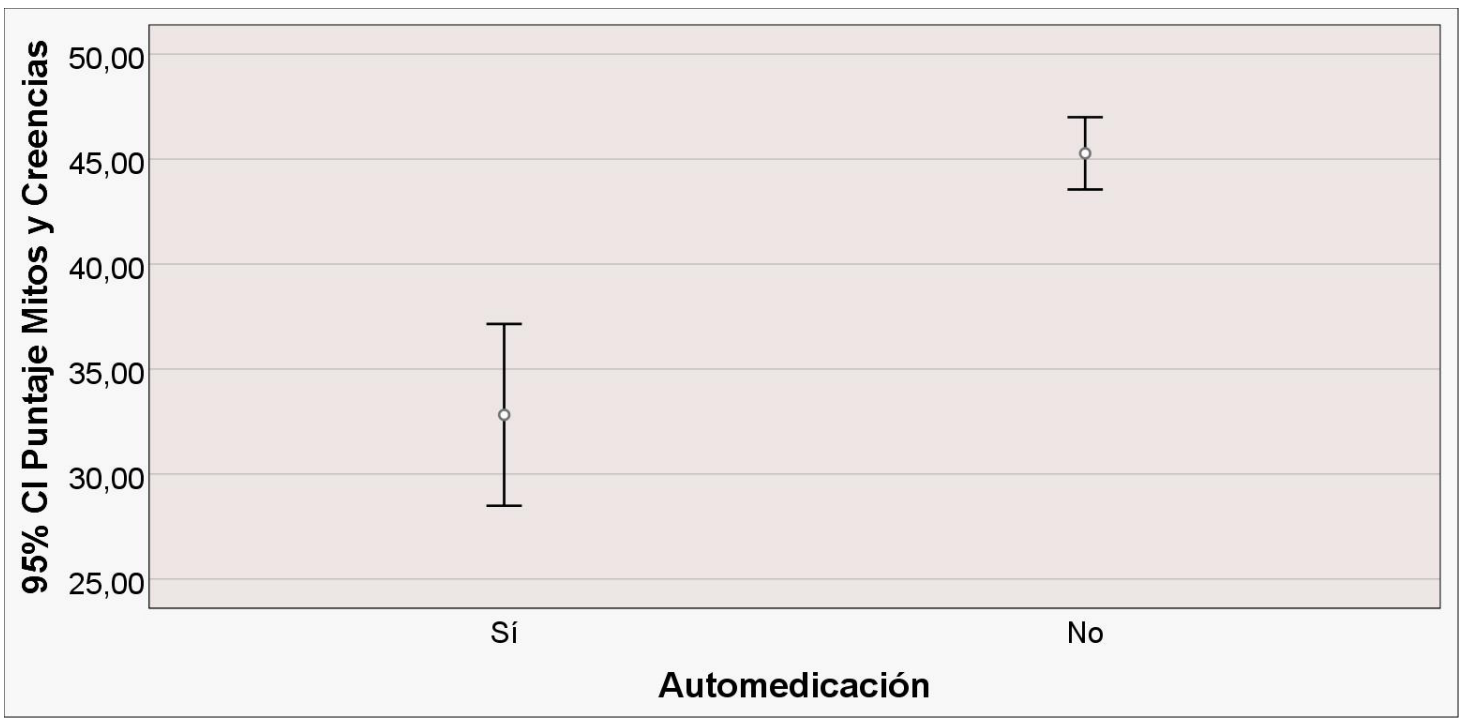

Figura 3. Puntaje de mitos y creencias según automedicación en adultos jefes de hogar, 2020 


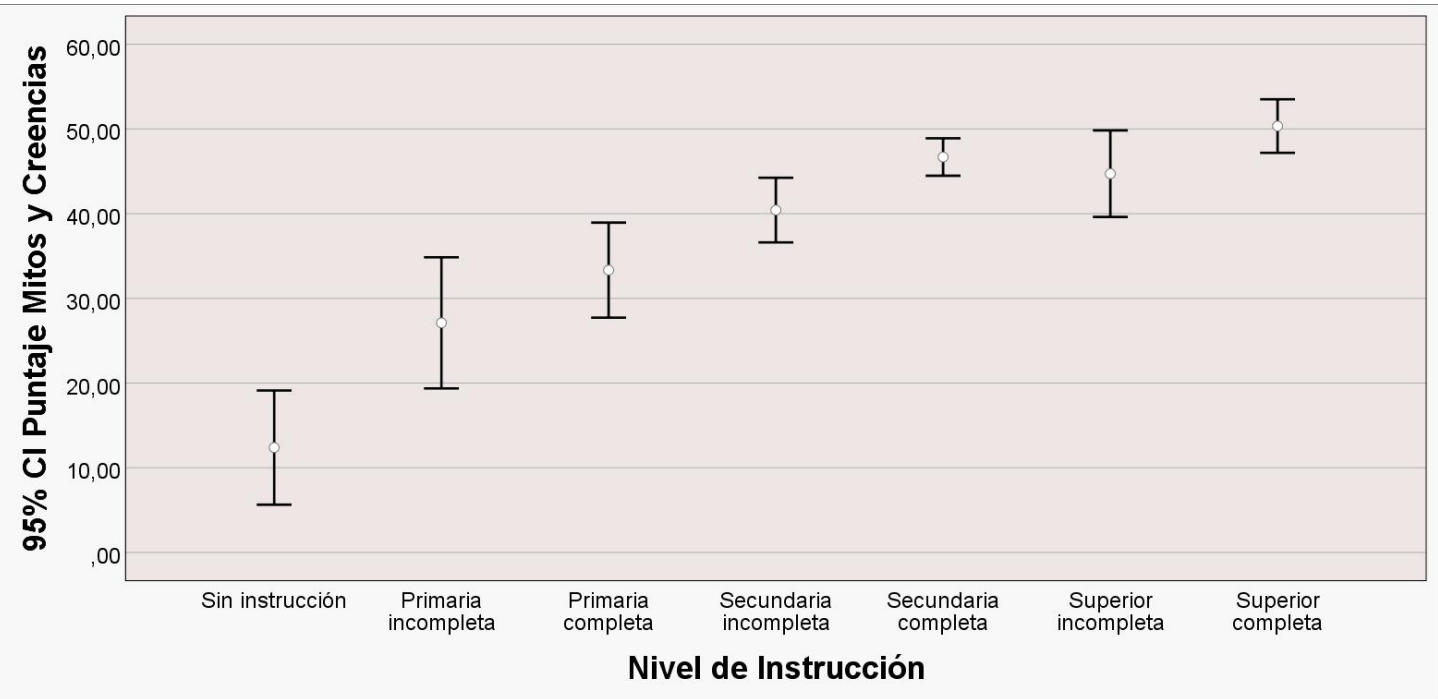

Figura 4. Puntaje de mitos y creencias según nivel de instrucción en adultos jefes de hogar, 2020

Asimismo, el grupo que no se automedicaba tenía buenos niveles de calificación de mitos y creencias (a mayor puntaje, mejor condición frente a mitos y creencias), al contrario del grupo que sí se automedicaba, donde existía un inadecuado nivel de calificación de mitos y creencias. Esta diferencia fue altamente significativa $(p<0,00)$ (Figura 3).

También existe una gran diferencia entre aquellos con menos instrucción versus aquellos que tienen un nivel más alto $(\mathrm{p}<0,00)$. A mayor nivel de educación, mejoran la condición respecto a tener mitos y creencias inadecuados (Figura 4).

\section{Discusión}

Durante el período de la pandemia por COVID-19, donde el distanciamiento social y el aislamiento domiciliario son algunas de las principales medidas preventivas. Muchas personas perciben estados exagerados de presencia de síntomas o son minimizados por algunos antecedentes de sintomatología respiratoria crónica como la presencia de rinitis alérgica estacional. En una gran proporción optan por autodiagnosticarse y automedicarse, ya sea en procesos propios o realizando recomendaciones a familiares y amigos a través de una cadena interminable de comunicación distorsionada. Aunque esta práctica ha ocurrido incluso antes de la emergencia, es importante recordar los riesgos de elegir medicamentos sin la supervisión de un experto. Esto, potenciado por una alta frecuencia de mitos y creencias que se dispersan principalmente por las redes sociales, hace que el sistema de comunicación se convierta en un arma de apoyo sanitario o en una de las principales falencias asociadas a complicaciones en el brote. La experiencia en el campo ha enseñado que uno de los factores asociados a pacientes que llegan complicados al servicio de emergencias COVID-19 es la tardía asistencia ya sea por percibir inadecuadamente el riesgo de padecer la enfermedad o por haber iniciado un tratamiento empírico que llevó a un retraso en la atención médica. La oportunidad de asistencia en el tratamiento del paciente es el arma más importante frente al COVID-19. La aparición de complicaciones en la enfermedad o el elevado riesgo de fallecimiento por acceso tardío a consulta especializada es una relación que aún queda por medir a través de futuros trabajos de investigación. Se encontró una elevada asociación de variables como inadecuada percepción de riesgo, presencia elevada de mitos y creencias, así como un grupo que se automedicaba, específicamente para COVID-19, por influencia de recomendaciones impartidas empíricamente por redes sociales.

Sánchez-Tarragó refirió que las noticias falsas se propagan más rápido y más fácil que este virus y son igualmente peligrosas ${ }^{11}$. El peligro de medias verdades o información falsa hace que las personas realicen su propia búsqueda informativa, en especial en internet, y desde allí, por una sensación de "prevención oportuna", inician tratamientos empíricos o deciden asistir a los servicios sanitarios cuando ven que el resultado de su propia conducta no fue efectivo. Lake et al. ${ }^{21}$ opinan que las autoridades de salud pública deben monitorear la situación de cerca, en especial en las poblaciones y sus conductas, cuestión que apoyamos. En esta 
sociedad, una de las principales falencias es que se dejó abiertamente que la opinión vertida en sistemas de comunicación informales y redes sociales superara la orientación oficial apoyada por experiencia científica. Se percibió una desatención de las autoridades sanitarias de rebatir oportunamente la conducta empírica, en especial en una población donde el nivel de instrucción no es el deseado y, por características históricas, los mitos y las creencias son una barrera que nunca se logró superar apropiadamente. No se tuvo una lucha organizada para rebatir la desinformación, así como para controlar de forma adecuada el expendio de productos farmacéuticos y de los otros que se vendieron en forma indiscriminada, lo cual hizo de este un negocio muy lucrativo para empresas formales e informales.

Pérez Fuentes et al. ${ }^{9}$ refieren que la percepción de la enfermedad juega un papel importante en la adaptación psicológica del individuo dan a entender que la lucha no es solo clínica o epidemiológica, al contrario, la estrategia organizada de percepción de riesgo es una manera eficiente de evitar principalmente las complicaciones y la muerte. En este aspecto, se hace necesario indagar profundamente sobre este dilema y presentar informes confiables que permitan que las autoridades sanitarias centren también su atención en el monitoreo de la percepción de estar en riesgo en poblaciones y grupos humanos por estratos. Se hace necesario validar una herramienta que pueda medir los procesos de conducta de las enfermedades causadas por el coronavirus. Además de la aquí presentada se deben proponer otras que puedan ser usadas para evaluar la percepción de las amenazas COVID-19 en la población adulta pero también en personas jóvenes, por sus características especiales de conducta. El abordaje de la población joven será muy necesario, ya que en la sociedad estudiada son los principales "vectores" de transmisión a poblaciones en riesgo como la población adulta y adultos mayores. La verificación de este instrumento ayuda a representar el progreso de COVID-199. Lo observado aquí es que las conductas inadecuadas como la automedicación no son diferentes según factores sociodemográficos. Las fuentes de información más usadas son las redes sociales con frecuencias por encima del $50 \%$, diarios o revistas 35,2\%, $15 \%$ la televisión y $10 \%$ la radio. La radio no fue de mayor uso comparado con la señal abierta de la televisión o el acceso a redes. Salaverría et $a l .{ }^{5}$ en su investigación “...tipología de los 'bulos' sobre la Covid-19" muestra que la mala información sobre el coronavirus se propaga principalmente en las redes sociales. Los resultados muestran que, además de producir muchas bromas en salud y ciencia, esta epidemia también causó la propagación de muchos contenidos políticos y gubernamentales incorrectos que generaron descontextualización y engaño. Es muy importante tener presente la oportunidad de aprovechar estas redes con el apoyo de la población joven como un recurso que puede ser potenciado eficientemente para generar información adecuada y orientadora. Los jóvenes podrían generar nuevas tendencias de lucha contra enfermedades como la presente pandemia. En sociedades como esta, la población joven, dotada de mejores recursos de comunicación, es la menos aprovechada y en muchas regiones, totalmente postergada.

Garbee et al. refieren que las personas con más conocimiento tienden a acumular más y reconocen que la ansiedad genera una sensación de falta de percepción de riesgo ${ }^{10}$ y que es población generalmente adulta a cargo del hogar. Una cuestión muy preocupante es que no hay estudios que aborden estos temas. Las características de aislamiento y automedicación recién se están explorando en las diferentes regiones de Perú. En este estudio, el $64 \%$ de la población reconoce que su aislamiento fue irregular y el $20,8 \%$ no lo hizo o no le interesó hacerlo. Solo un 15,2\% refiere haber guardado un aislamiento estricto. En aquellos que se automedicaron, el 48,6 \% consumió Ivermectina, seguido de un $45,9 \%$ de dióxido de cloro. Este último producto no cuenta con ningún respaldo de publicaciones científicas y su uso es muy discutido. Además de esto, el $18,4 \%$ tenía ya almacenado Ivermectina, seguido de un 17,2 \% de Azitromicina, principalmente, en espera de usarlos ante cualquier síntoma. Ya anteriormente Guerra Ramírez de Colunche et al. midieron el porcentaje de antibióticos dispensados en las farmacias sin receta médica en la ciudad de Lima, donde el 96,7 \% no requirieron recetas para distribuir antibióticos. La proporción de antibióticos sin receta en farmacias indica una alta incidencia de automedicación ${ }^{13}$. Este escenario se encontró la pandemia y se convirtió en una de las principales falencias del sistema sanitario ya que desnudó uno de los principales descuidos sanitarios, que requerirá en el futuro una mayor preocupación por los entes responsables de la salud de las poblaciones. Como se puede apreciar, lo multifactorial del actual fenómeno pandémico lleva a priorizar acciones que serán el sustrato de futuras investigaciones en el medio.

\section{Conclusiones}

Referente al consumo preventivo de productos farmacológicos en el grupo automedicado, consumieron ivermectina $48,6 \%$ y dióxido de cloro $45,9 \%$. Del total 
del grupo de estudio, el $18,4 \%$ tenía ya almacenado ivermectina seguido de un $17,2 \%$ de azitromicina principalmente. Y los mitos y creencias más frecuentes fueron "rociarse con alcohol o cloro mata el virus" "los remedios caseros pueden curar o prevenir el coronavirus" "el calor puede matar el virus" "las personas contagiadas con el virus morirán irremediablemente", "el lavado de manos constante mata el virus" "la gárgara de agua con sal mata el virus". Existió diferencias significativas según edad ( $\mathrm{p}:<0.05)$, nivel de instrucción ( $\mathrm{p}: 0.00)$. La automedicación estuvo asociada a baja percepción de riesgo (p:0.00) y presencia de mitos y creencias (p:0.00).

\section{Conflicto de interés}

Este estudio fue realizado con el consentimiento de la Escuela Profesional de Medicina Humana de la Universidad Privada de Tacna. Los autores declaran haber participado en el estudio en todas sus partes, que los datos consignados son reales y que no existe conflictos de interés.

\section{Referencias}

1. Sahoo S, Padhy SK, Ipsita J, Mehra A, Grover S. Demystifying the myths about COVID-19 infection and its societal importance. Asian J Psychiatry. 2020; 54: 102244. doi: https://doi.org/10.1016/j. ajp.2020.102244

2. Yupari-Azabache I, Bardales-Aguirre L, RodríguezAzabache J, Barros-Sevillano J. S, Rodríguez-Díaz Á. Factores de riesgo de mortalidad por COVID-19 en pacientes hospitalizados: Un modelo de regresión logística. Rev. Fac. Med. Hum. 2021; 21(1): 19-27. doi: http://dx.doi.org/10.25176/rfmh.v21i1.3264

3. Heymann DL, Shindo N. COVID-19: what is next for public health? The Lancet. 2020; 395(10224): 542-545. doi: 10.1016/S0140-6736(20)30374-3

4. Ni MY, Yang L, Leung CMC, Li N, Yao XI, Wang Y, et al. Mental health, risk factors, and social media use during the COVID-19 epidemic and cordon sanitaire among the community and health professionals in Wuhan, China: Cross-sectional survey. JMIR Ment Health. 2020; 7(5). doi: 10.2196/19009

5. Salaverría R, Buslón N, López-Pan F, León B, López-Goñi I, Erviti M-C. Desinformación en tiempos de pandemia: tipología de los bulos sobre la Covid-19. El Prof Inf EPI. 2020; 29(3). https:// doi.org/10.3145/EPI

6. Organización Mundial de la Salud. Nuevo coronavirus 2019; [ https://www.who.int/es/ emergencies/diseases/novel-coronavirus-2019
7. Merchant RM, Lurie N. Social media and emergency preparedness in response to novel Coronavirus. JAMA. 2020; 323(20): 2011-2012. doi:10.1001/ jama.2020.4469

8. World Health Organization. Panel de Control de coronavirus (COVID-19) de la OMS. Situación global. 2021; https://covid19.who.int

9. Pérez-Fuentes $M$ del $C$, Molero Jurado $M$ del M, Oropesa Ruiz NF, Martos Martínez Á, Simón Márquez M del M, Herrera-Peco I, et al. Questionnaire on perception of threat from COVID-19. J Clin Med. 2020; 9(4): 1196. doi: https://doi.org/10.3390/jem9041196

10. Garbe L, Rau R, Toppe T. Influence of perceived threat of Covid-19 and HEXACO personality traits on toilet paper stockpiling. PLOS ONE. 2020; 15(6): e0234232. doi: https://doi.org/10.1371/ journal.pone. 0234232

11. Sánchez-Tarragó N. Desinformación en tiempos de COVID-19: ¿Qué podemos hacer para enfrentarla? Rev Cuba Inf En Ciencias de la Salud.2020; 31(2).

12. Ruiz ME. Risks of self-medication practices. Curr Drug Saf. 2010; 5(4): 315-323. doi: 10.2174/157488610792245966

13. Guerra Ramírez De Colunche LA, Garfias Mallqui I. Estudio del expendio de los antibióticos sin receta médica en boticas y farmacias en el distrito de los olivos-lima, enero-junio 2019. Univ María Aux - UMA. http://repositorio.uma.edu.pe/handle/ $\mathrm{UMA} / 221$ ? show=full

14. Wolf LJ, Haddock G, Manstead ASR, Maio GR. The importance of (shared) human values for containing the COVID-19 pandemic. Br J Soc Psychol. 2020; 59(3).

15. Lajús Barrabeitg, G. Análisis de algunos comportamientos nocivos de la población cubana frente a la COVID-19. Rev. Haban Cienc Méd. 2021; 19(6).

16. Loewenstein GF, Welch N. Risk as feelings. Psychol Bull. 2001; 127(2): 267-286. https://doi. org/10.1037/0033-2909.127.2.267

17. Wiswanath Lab de Harvard Chan School of Public Health y el Dana-Farber Cancer Institute (DFCI). Why is it important to combat misinformation about COVID-19 vaccines? India Research Center. 2021. https://www.hsph.harvard.edu/india-center/mythsvs-facts/

18. Zhang N, Fielding R, Soong I, Chan KKK, Lee C, $\mathrm{Ng}$ A, et al. Psychometric assessment of the Chinese version of the brief illness perception questionnaire in breast cancer survivors. PLOS ONE. 2017; 12(3): e0174093. https://doi.org/10.1371/journal. pone. 0174093 
19. Pacheco-Huergo V, Viladrich C, Pujol-Ribera E, Cabezas-Peña $C$, Núñez $M$, Roura-Olmeda $P$, et al. Perception in chronic illnesses: linguistic validation of the revised Illness Perception Questionnaire and the Brief Illness Perception Questionnaire for a Spanish population. Aten Primaria. mayo de 2012; 44(5): 280-287. https://doi.org/10.1016/j. aprim.2010.11.022

20. Organización Mundial de la Salud. Consejos para la población acerca de los rumores sobre el nuevo coronavirus (2019-nCoV). 2020; https:// www.who.int/es/emergencies/diseases/novelcoronavirus-2019/advice-for-public/myth-busters

21. Lake MA. What we know so far: COVID-19 current clinical knowledge and research. Clin Med Lond Engl. 2020; 20(2): 124-127. doi: $10.7861 /$ clinmed.2019-coron 